
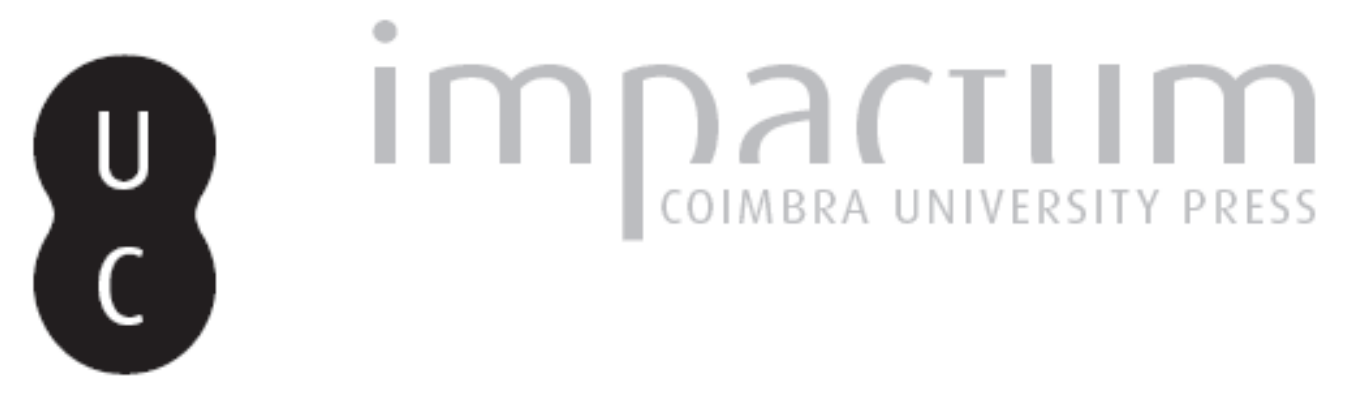

\title{
A relação entre o poder legislativo e o poder executivo no contrato social de Jean- Jacques Rousseau
}

Autor(es): $\quad$ Alves, Vital Francisco C.

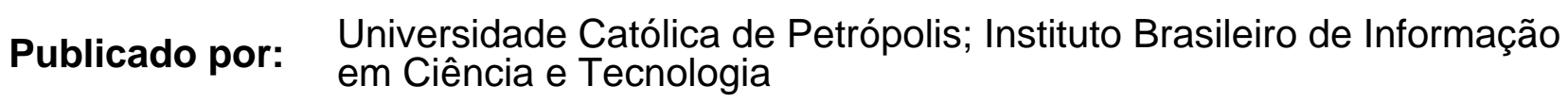

URL

persistente:

URI:http://hdl.handle.net/10316.2/33084

DOI: $\quad$ DOI:http://dx.doi.org/10.14195/1984-6754_2_6

Accessed : $\quad$ 26-Apr-2023 14:38:27

A navegação consulta e descarregamento dos títulos inseridos nas Bibliotecas Digitais UC Digitalis, UC Pombalina e UC Impactum, pressupõem a aceitação plena e sem reservas dos Termos e Condições de Uso destas Bibliotecas Digitais, disponíveis em https://digitalis.uc.pt/pt-pt/termos.

Conforme exposto nos referidos Termos e Condições de Uso, o descarregamento de títulos de acesso restrito requer uma licença válida de autorização devendo o utilizador aceder ao(s) documento(s) a partir de um endereço de IP da instituição detentora da supramencionada licença.

Ao utilizador é apenas permitido o descarregamento para uso pessoal, pelo que o emprego do(s) título(s) descarregado(s) para outro fim, designadamente comercial, carece de autorização do respetivo autor ou editor da obra.

Na medida em que todas as obras da UC Digitalis se encontram protegidas pelo Código do Direito de Autor e Direitos Conexos e demais legislação aplicável, toda a cópia, parcial ou total, deste documento, nos casos em que é legalmente admitida, deverá conter ou fazer-se acompanhar por este aviso.

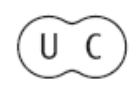



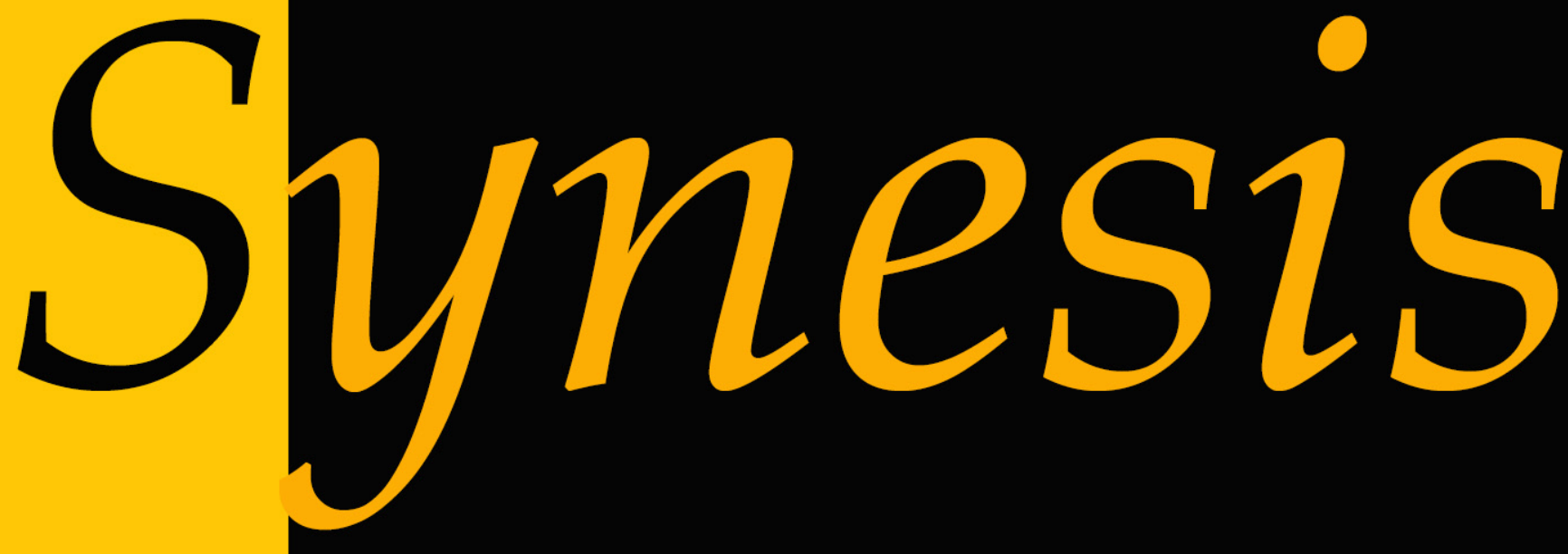

Revista do Centro de Teologia e Humanidades ISSN 1984-6754

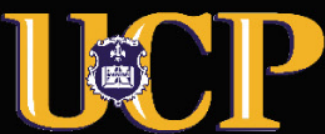




\title{
A Relação entre o Poder Legislativo e o Poder Executivo no Contrato Social DE JEAN-Jacques Rousseau
}

\begin{abstract}
Vital Francisco C. Alves ${ }^{1}$
Resumo: No pensamento de Rousseau, o soberano, desempenha o poder legislativo e pode ser compreendido como o poder pelo qual a vontade se manifesta. Enquanto, o governo ou o poder executivo é a força que se empenha em aplicar a vontade do soberano. Assim, por sua natureza, o poder legislativo e o poder executivo são poderes distintos, pois um é a vontade e o outro a força. Em vista disso, a boa relação entre vontade e força é essencial para o bem estar da ordem política preconizada pelo pensador de genebra. Para tanto, é necessário que haja um equilíbrio entre ambas, estabelecido a partir da consistente separação entre o poder legislativo e o poder executivo. Com o objetivo de compreender $A$ relação entre o poder legislativo e o poder executivo no Contrato Social de Rousseau, nossa análise se preocupará em tratar de três aspectos fundamentais: primeiramente, investigaremos como Rousseau distingue o poder legislativo do poder executivo, ou seja, nos atentaremos para um provável entendimento da definição de ambos os poderes e da função desempenhada por cada um deles. Em segundo lugar, examinaremos quais os possíveis problemas podem acometer a constituição política no caso de uma separação de poderes deficiente ou precária. Por fim, analisaremos os desafios para uma relação saudável entre os poderes e quais recursos apresentados por Rousseau alvejam assegurar a boa relação entre o poder legislativo e o poder executivo.
\end{abstract}

Palavras-chave: Poderes; legislativo; executivo.

Abstract: According to Rousseau's thought, the sovereign, performs the legislative power and can be understood as the power in which the will expresses itself while the government on the executive power is the strength that works hard to execute the will of the sovereign. Therefore, by its nature, the legislative power and the executive power are distinct because one is the will and the other the strength. Indeed, a good relation between the will and the strength is essential, for the well-being of the political order stood by the Geneve's philosopher. That's why it's necessary to have a balance for both, established by solid distinction between the legislative and executive power. Aiming at understanding "the relation between legislative and executive powers in Rousseau's Social Contract", our analysis will worry about dealing with three main aspects: first, we will investigate how Rousseau distinguishes the legislative and

1 Mestrando em Filosofia pela UFG

http://www.ucp.br/html/joomlaBR/synesis/synesis.htm 
executive power. It means that we will focus on the possible understanding of the definition of both powers and its respective functions. Second, we will examine which possible problems can assault the political constitution in case of a power separation being it deficient or precarious. At last, we will analyze the challenges of a healthy relation between both powers and which resources presented by Rousseau aim to ensure a good relation between legislative and executive powers.

Key-words: powers; legislative; executive.

\subsection{A relaÇÃo entre o PODER Legislativo E O PODER EXECUtivo}

$\mathrm{Na}$ doutrina política de Rousseau, o soberano, ocupa o poder legislativo e pode ser considerado o poder que manifesta a vontade, enquanto o governo ou o poder executivo é a força empenhada em aplicar a vontade do soberano, nas palavras de Rousseau “o corpo político tem os mesmos móveis. Distinguem-se nele a força e a vontade, esta sob o nome de poder legislativo e aquela, de executivo (Do Contrato Social, p. 135). Na visão de Derathé, estudioso da obra de Rousseau, no projeto político do genebrino, por sua natureza, o poder executivo e o poder legislativo são poderes distintos. Um é a força e outro a vontade. Ou ainda, um é o poder que age e outro o poder que quer. Mas talvez isso não seja o essencial, afirma ele:

O que caracteriza o poder executivo, é que ele é conduzido a tomar decisões particulares e que, de fato, não pode ser exercido pela vontade geral. O poder legislativo é, ao contrário, a atividade própria da vontade geral, porque ela age somente pelas leis ${ }^{2}$.

2 “Ce qui caractérise la puissance exécutive, c'est qu'elle est amenée à prendre dês décisions particulières et que, de ce fait, elle ne peut être exercée par la volonté générale. La puissance législative est, au contraire, l'activité propre de la volonté génerale, puisque celle-ci ne peut agir que par des lois. Les rapports de l'executive e du legislatif chez J-J Rousseau" (Robert Derathé, p. 155/6 ; tradução do autor). 
A boa relação entre vontade e força é essencial para o bem estar da ordem política, para isso é necessário a existência de um equilíbrio entre ambas, estabelecido a partir da separação entre estes dois poderes, pois a vontade geral não conseguirá produzir o resultado esperado, sem um instrumento adequado capaz de operar uma união saudável entre força e vontade.

O propósito de Rousseau ao fixar de maneira estrita a função de cada poder, demonstrando as qualidades de cada um deles, é proteger os cidadãos de posturas arbitrarias individuais ou de grupos dentro da ordem política, que possam vir a violar a liberdade e a igualdade entre os cidadãos. Sendo assim, o projeto político defendido pelo pensador de Genebra assegura a atuação do soberano e do governo somente pela lei, o qual limitará qualquer tentativa de uma vontade despótica se impor. À rigor, uma distinção consistente dos poderes implica em entender que eles têm suas limitações ao se relacionarem com as questões das quais tratarão.

Nesse sentido, o poder executivo encontra-se cerceado pela lei engendrada pelo legislativo. Dessa maneira, Rousseau tenciona delimitar a atuação do soberano, isto é, ele deve apenas produzir leis hábeis o suficiente para enunciarem a vontade geral, enquanto o governo deverá colocar as leis em prática e não se posicionar acima delas. Mesmo porque, no Contrato Social as leis estão acima de todos os cidadãos e não só do governo. Ao dar primazia a essa localização da lei, Rousseau resguarda a liberdade e assegura que um homem não se torne dependente de outro.

Considerando que, para o autor do Contrato Social, o relacionamento entre os poderes se configura em uma relação entre um poder superior, o legislativo, e outro submisso, o executivo. A falta de discernimento entre tais poderes pode gerar uma desestabilização na constituição política, porque quanto mais membros o governo tiver, menos capacidade de agir ele terá. Ao mesmo tempo, se a soberania absorver a função do poder executivo, o 
governo suportará tantas partes como a quantidade de cidadãos que possui, tal fato resultará no cumprimento de sua função somente pela metade. Por outro lado, a atuação do governo também não pode ser menor da que lhe é designada, pois, assim, a vontade particular ganhará força e atentará contra a autoridade soberana.

Aos olhos de Rousseau, a incapacidade de reconhecer a diferença entre o soberano e o governo pode causar a degenerescência do corpo político, se não estiverem claras as limitações comuns reveladoras do papel legislativo da soberania. Destarte, a noção de vontade geral, defendida pelo autor genebrino implica na separação entre a soberania e o governo porque delimita o espaço da vontade particular e da atuação dos poderes. Logo, para Rousseau quanto mais membros o governo tiver, mais próximo, no que diz respeito ao tamanho, ele estará do soberano, com isso, sua vontade estará mais próxima da vontade geral.

\subsection{A TENSÃo ENTRE OS PODERES}

Não há como negar que a relação entre soberano e governo cria uma tendência do governo ou poder executivo de subjugar o poder legislativo e isso instaura uma tensão, já que "o Governo despende um esforço contínuo contra a soberania. Quanto mais esse esforço aumenta, tanto mais se altera a constituição" (ibidem I, p. 173) e tal fato pode prejudicar a legitimidade do governo, pois ela depende da prevalência da vontade geral e do equilíbrio na ordem política. Para a conservação da vontade geral e da saúde da ordem pública, é necessário o respeito às funções e limitações de ambos os poderes. Não obstante, essa tensão entre eles é latente, ao passo que o fato de o governo possuir muitos magistrados o leva a supor que tem mais poderes em relação aos demais cidadãos e, como efeito, supõe poder exigir mais deles do que ele próprio cumprirá.

O objetivo de Rousseau, ao pensar a instituição do governo, é 
formulá-la em concordância com os fundamentos da doutrina do Contrato Social e preconizá-la como a mais plausível entre as possibilidades. Tal objetivo vai ao encontro da tentativa do genebrino em formular uma constituição política que tenha instrumentos para combater o mau uso do poder e possua princípios capazes de colaborem para sua durabilidade. Em vista disso, Rousseau declara:

se quisermos formar uma instituição duradoura, não pensemos, pois, em torná-la eterna. Para ser bem sucedido não é preciso tentar o impossível, nem se iludir com dar à obra dos homens uma solidez que as coisas humanas não comportam. O corpo político (...) começa a morrer desde o nascimento e traz em si mesmo as causas de sua destruição (...) ele pode ter uma constituição mais ou menos robusta e capaz de conservá-lo por mais ou menos tempo (Ibidem I, p. 177).

Assim, na perspectiva de Rousseau, mesmo tendo em vista alguns problemas naturais à constituição política, não se podem realizar prognósticos concretos, mas apenas hipóteses sobre os abusos perpetrados pelo governo ou sua propensão a corromper-se, nesse sentido, é clara a mobilização do pensador de Genebra em estabelecer leis que tentem coibir os abusos mais freqüentes e propicie o bem estar e a durabilidade do Estado. Como conseqüência, as leis são os meios para asseverar a saúde da constituição política.

A lei é a essência da ordem política e localiza-se acima dos cidadãos. Ao forjar a instituição do governo, a partir das leis postuladas pelo povo, Rousseau confronta as doutrinas que defendem a idéia de que o cerne do Estado está no governo e não consideram o direito de conquista, o pacto de associação e as leis fundamentais como objeto de convenção. Tal doutrina 
é utilizada por Rousseau para explicitar como alguns governos surgem e com o intuito de instaurar outra possibilidade na qual a essência do Estado seja a lei e não o governo. Portanto, o mais relevante é a existência de leis enunciadoras da vontade geral e posicionadas acima de todos os cidadãos e não a presença de um governo.

Em vista disso, na filosofia política de Rousseau, a obediência de todos os cidadãos às leis é primordial e a insistência do genebrino em resguardar a soberania no povo, detentor do poder legislativo e a sustentação da lei acima dos indivíduos está em perfeita congruência com o seu pensamento. Nessa ordem política, o soberano dar à luz as leis e designa a aplicação delas ao governo, ambas as partes, ao desempenharem suas funções consolidam a constituição política. Assim, soberano e governo encontram-se unidos em prol da mesma causa, isto é, a conservação do Estado e assumem compromissos de reciprocidade. Por conseguinte, o governo deve ser uma força pública empenhada em colocar em prática as orientações da vontade geral.

A dificuldade política reside no fato de que cada indivíduo possui uma vontade particular e ele está propenso a escolher pela satisfação dela, ao invés da de outrem. Porém, o soberano por sua vez, igualmente, tem uma vontade que é geral em relação aos seus membros e outra particular concernente ao Estado. A relação entre essas duas vontades produz uma tensão entre o soberano e o governo, pois a vontade particular atentará contra a vontade geral, fundamento essencial da ordem política, conseqüentemente, o Estado adoece e tende a se dissolver. Assim,

\footnotetext{
"Rousseau sustenta que os Estados perecem porque o poder executivo tende a se proclamar independente do poder legislativo ou, em outras palavras, que o governo usurpa a soberania e não administra mais o Estado segundo as leis. O mal
} 
é inevitável, não somente porque o governo tem a força nas mãos, mas também porque ele constitui um 'corpo que é intermediário' e não se conforma em ser um corpo subordinado ${ }^{3}$.

Na natureza do governo, portanto, a vontade do corpo tende a ser o móvel pelo qual tentará tomar à força a posição da soberania e incutir sua vontade acima da deliberação das leis.

Em tal caso, Rousseau preconiza que, mesmo a ação do governo sendo limitada pelas leis e seu poder norteado pela vontade dos cidadãos, ele atentará contra o soberano, procurando amiúde alargar seu poder frente a esse. Tal perigo é iminente porque constitui um traço da natureza do governo. Desse modo, o intuito do governo de tornar-se uma autoridade superior ao soberano é algo inevitável e caracteriza o corpo político desde sua formação. Isso ocorre, porque há uma constante solicitação do Estado para que as leis sejam aplicadas e como essa tarefa é desempenhada pelo governo, esse tende a considerar sua função mais importante comparada a do soberano.

Ao julgar sua tarefa mais relevante em relação a do soberano, o governo se sentirá estimulado a usurpar essa autoridade. É peculiar à natureza do poder executivo comprovar sua força e atuar de modo ininterrupto, não obstante, tal ação do governo é perniciosa para o bem estar ou o equilíbrio das instituições políticas. Agindo assim o governo se inclina também em procurar convencer o povo de que as assembléias são uma concessão à qual ele permite com o intuito dos indivíduos terem um espaço para agirem e deliberarem. À revelia, o governo tentará persuadir o povo da suposto ineficácia das assembléias devido a elas serem demoradas e defenderá que

3 Rousseau a toujours soutenu que les États périssent parce que la puissance exécutive tend à se rendre indépendante de la puissance législative ou, autrement dit, que le gouvernement usurpe la souveraineté et n'administre plus l'État selon les lois. Le mal est inévitable, no seulement parce que le gouvernement a la force em main, mais aussi parce qu'il constitue um corps et que ce "corps intermédiare" ne se resine pás à etre un corps subordonné - Ibidem II p. 160/1 (tradução do autor).

http://www.ucp.br/html/joomlaBR/synesis/synesis.htm 
são nocivas aos interesses particulares dos membros dos quais a compõe. A partir desse procedimento, o governo estará tentando dissuadir o povo de que o soberano extrai sua força e o impede de agir amplamente e com mais velocidade. O seu objetivo, com essa postura é, sobretudo, convencer o povo da falta de necessidade da autoridade soberana e persuadi-lo de que para o poder do Estado ser mais eficiente é fundamental a concentração de ambos os poderes apenas nas mãos do governo.

Entretanto, se o governo assumir também o poder legislativo, ele passará a julgar as leis conforme seus próprios interesses e se colocará dissimuladamente contra a vontade geral recomendada pelo nosso autor. Nesse caso, as leis metamorfosear-se-ão em disfarces dos quais um interesse particular modifica e ludibria a face do interesse comum, assim o instrumento que preserva os homens da dependência de outrem é transformado em um mecanismo de dominação pelo governo. Logo, a legitimidade e a unidade, defendidas por Rousseau, degeneram e a força concentrada da autoridade do governo passa a se impor contrariando, assim, o equilíbrio e a saúde da constituição política. Com efeito, o dever e a liberdade da qual dependem da legitimidade e da coesão para sobreviver, acabam por extenuarem-se, pois as leis que devem refletir a vontade geral, portanto, o interesse comum, expressará vontades particulares e além do mais, o poder estará centralizado.

O propósito de Rousseau, ao pensar a organização política, é criar um Estado saudável e duradouro, mesmo tendo em vista que ele tende a degenerar-se com o tempo. Assim, apesar de se tratar de um mal fatal e inerente à natureza do governo, é preciso saber, se a teoria política de Rousseau dá conta, por intermédio de algum remédio eficaz, de sanar as tensões entre os poderes, provenientes das tentativas de usurpação do governo em relação ao soberano e, se essa postura, consegue alcançar o bem-estar e a durabilidade desejados. 


\section{3 - Conclusão: Medidas Para Remediar a tensão entre os PODERES}

Compreendendo a gênese do mal do governo como algo natural e intimamente ligado ao corpo político, Rousseau não hesita em apresentar um remédio para espreitar as ações do governo e outro para sanar possíveis conseqüências de suas tentativas de usurpação. Os remédios apresentados por Rousseau visam promover a saúde e a durabilidade do Estado. Para tanto, na visão do genebrino, preservar a obediência do poder executivo ao legislativo, com o passar do tempo, tornar-se uma tarefa árdua e improvável. A dificuldade de manter tal subordinação pode ser entendida por dois aspectos fundamentais: em primeiro lugar, no que concerne à atividade do poder executivo ser marcada pela força e a atuação do soberano encontra-se restrita à explicitação de suas vontades. Em segundo, o fato do poder executivo ser caracterizado pela freqüência e ação, à medida que o legislativo atua com muitas interrupções e é inconstante.

Em face de disso, Rousseau ao elaborar sua proposta política busca estabelecer providências capazes de atingir os resultados almejados e dirigir a atuação do poder legislativo na sua relação com o executivo. Nesse sentido, as duas medidas adotadas pelo cidadão de Genebra para aliviar e adiar os efeitos do mal ou do problema das tensões entre os poderes são: primeiramente, separar os diversos conselhos e mudar com intervalos regulares os membros mais atuantes do poder executivo. Com essa medida, Rousseau acredita que o poder executivo se torna mais submisso ao poder legislativo e isso impede as tentativas do governo de usurpar o poder soberano. A segunda medida sugerida por Rousseau, consiste na criação de assembléias permanentes e periódicas do legislativo com objetivo de interromper temporariamente o poder executivo, pois "no momento em que o povo se encontra legitimamente reunido em corpo soberano, cessa qualquer jurisdição do Governo, suspendese o poder executivo" (Ibidem I, p.183), conseqüentemente, elas ressaltariam a subordinação do poder executivo e suspenderiam sua atividade quando 
fossem realizadas.

Ao observar as medidas propostas por Rousseau, percebemos como ele pretende resolver o problema exposto e verificamos que tal mal se origina do fato da atuação do poder executivo ser contínuo enquanto a atividade do legislativo é assinalada por interrupções constantes. Desse modo, as providências rousseauístas objetivam, por um lado, assegurar a atuação freqüente do poder legislativo e por outro, fazer alterações constantes no executivo. Essas medidas são fundamentais para garantir a saúde e a conservação prolongada da ordem política. Entretanto, para elas serem eficazes é necessário que o executivo seja amiúde obrigado a fornecer informações acerca de suas ações ao poder legislativo, porque sem a delimitação desse dever o executivo tenderá a proceder da maneira mais conveniente a si. Assim, as providências apresentadas por Rousseau sugerem que o poder legislativo controle freqüentemente o executivo, exigindo dele o fornecimento de esclarecimentos concernentes as suas atuações e, apenas se o poder executivo não se mostrar propenso a aceitar essa condição, será necessário utilizar o segundo dispositivo, isto é, o emprego das mudanças periódicas.

Ao defrontarmos com as questões que levantamos e investigamos ao longo desse estudo, percebemos que o pensamento de Rousseau proporciona ao leitor dois entendimentos ou conclusões possíveis depois de examinar os temas abordados: o primeiro é que a relação entre o poder executivo e o pode legislativo é marcada por tensões que se inclinam a violar a vontade geral, fundamento que perpassa toda a doutrina política de Rousseau e assevera a liberdade dos cidadãos por intermédio da lei e podem ser prejudiciais a legitimidade do governo. E a segunda conclusão exposta pelo autor do Contrato Social, refere-se à submissão do executivo ao legislativo, sendo que ela possui vários obstáculos difíceis de serem superados, além disso, ele explicita o fato do executivo trazer em seu bojo a aptidão para se impor como uma autoridade maior que o legislativo, pois a força de efetivar a vontade 
está concentrada em suas mãos.

\section{REFERÊnCIAS BibliogRáficas}

COBBAN, A. and J.H. Burns, "Rousseau's Du contrat social: some problems of translation", Political Studies, 10 (1962).

COHEN, J., "Reflections on Rousseau and democracy", Philosophy and Public Affairs, 15 (1980).

CRANSTON, M., Rousseau's Social Contract, in The Mask of Politics, M. Cranston (Londres,1973).

DERATHÉ, Robert. Jean-Jacques Rousseau e la Science Politique de son Temps. Paris. 1950.

FORTES, Luis Roberto Salinas. Rousseau: da teoria a prática. Ática. São Paulo, 1995.

GOLDSCHIMTH, Victor. "Les Principes de Systèmes de Rousseau” In: Anthropologie et Politiquie. Paris, J. Vrin, 1974.

MACHADO, Lourival Gomes. Homem e Sociedade na teoria política de J. J. Rousseau. São Paulo, Martins, 1968.

ROSENFELD, D., "Rousseau's unanimous contract and the doctrine of popular sovereignty”, History of Political Thought, 8 (1987

ROUSSEAU, Jean-Jacques. Du Contract Social. Paris: Galimard, 1964. 
Do Contrato Social. São Paulo: Abril Cultural, 1978.

SARIPLOS, Nicolas. Democratie et l'election proportionalle (la) a Rousseau. Paris. 1899

VAUGHAN, C. E. The political writings of Jean-Jacques Rousseau. New York, 1962.

VAUGHAN, C. E. Studies in the History of Political Philosophy Before and After Rousseau. Manchester, 1930. 